\title{
P75 neurotrophin receptor activates epidermal stem cell differentiation via ERK, JNK and AKT pathways
}

\author{
Xia Li ${ }^{1,2, *}$, Gaosong Yang ${ }^{3, *}$, Yongqian Cao ${ }^{1}$, Jincun Yang ${ }^{2}$ and Yibing Wang ${ }^{1}$ \\ ${ }^{1}$ Department of Burns and Plastic Surgery, Shandong Provincial Hospital Affiliated to Shandong University, Jinan, Shandong, \\ China \\ ${ }^{2}$ Department of Burns and Plastic Surgery, Weihai Municipal Hospital, Weihai, Shandong, China \\ ${ }^{3}$ Department of Burns and Plastic Surgery, The First Hospital of Shijiazhuang City, Shijiazhuang, Hebei, China \\ *These authors contributed equally to this work as the co-first author
}

Correspondence to: Yibing Wang, email: III777ccc555@163.com

Keywords: P75NTR; ESCs; differentiation; wound healing

Received: December 15, $2017 \quad$ Accepted: January 03, $2018 \quad$ Published: January 09, 2018

Copyright: Li et al. This is an open-access article distributed under the terms of the Creative Commons Attribution License 3.0 (CC BY 3.0), which permits unrestricted use, distribution, and reproduction in any medium, provided the original author and source are credited.

\section{ABSTRACT}

As reported, p75 neurotrophin receptor (p75NTR) is involved in activation and differentiation of epidermal stem cells (ESCs). However, the possible signaling pathways of p75NTR in ESCs remain unknown. In this study, p75NTR ${ }^{\text {vo }}$ ESCs were constructed to identify the role of p75NTR in cell differentiation. Here we found that P75NTR activated and promoted the differentiation of ESCs. Functionally, P75NTR significantly promoted cell proliferation and migration, and inhibited cell apoptosis. Mechanically, P75NTR stimulated the secretion of NGF in ESCs, and activated ERK, JNK and AKT signaling pathway. Finally in-vivo assay demonstrated that P75NTR effectively promoted wound healing in mice model. In conclusion, P75NTR activates differentiation of epidermal stem cells via ERK, JNK and AKT signaling pathways, and promotes the secretion of NGF and wound healing. Thus, P75NTR may favor skin wound healing in the clinical practice.

\section{INTRODUCTION}

Skin serves as a protective organ for mammals, which prevents pathogens, radiation etc $[1,2]$. The dysfunction of skin homeostasis usually result in dire consequences, involving acute, chronic inflammation or infected wounds $[3,4]$. And skin wound healing is an intrinsic self-saving chain reaction, which is crucial to facilitate the replacement of damaged or lost tissues. It is reported that epidermal stem cells are responsible for maintaining skin homeostasis [5]. However, the mechanisms of the differentiation of epidermal stem cells were not clear.

p75 neurotrophin receptor (p75NTR), together with the tyrosine kinase receptor tropomyosin-receptor kinase (Trk), is reported to mediate neurotrophin (NT) functions [6-8]. p75NTR serves as a low-affnity receptor to mediate diverse functions [9]. Generally, p75NTR is proteolytically cleaved by $\gamma$-secretase to generate intracellular domain after ligand activation $[10,11]$. It is reported that p75NTR interacts with a variety of proteins [12] that in turn induce different pathways [13]. This interaction allows p75NTR to play an important role in the regulation of some processes, such as proliferation, migration and differentiation [14]. However the potential signaling pathways that p75NTR participated in ESCs remain unknown.

In the present study, firstly, we examined the expression of stem cell bio-makers and p75NTR using western blot. And then, we investigated the related signalling pathways, involving ERK, JNK and AKT. Finally, wound healing assay was performed in mice model. Our findings indicated that P75NTR may favor skin wound healing in the clinical practice. 


\section{RESULTS}

\section{Isolation of ESCs and transfection of p75NTR}

To elucidate the role of $\mathrm{p} 75 \mathrm{NTR}$ in the progression of ESCs, we firstly isolated ESCs from newborn mice. And then, p75NTR ${ }^{\mathrm{vo}}$ ESCs were constructed and subjected to western blot. We found that $\mathrm{p} 75 \mathrm{NTR}$ expression was markedly increased in p75NTR ${ }^{\text {vo }}$ ESCs compared with that in empty vector (EV) ESCs (Figure 1A). $\left({ }^{*} p<0.05\right)$. Furthermore, we examined the expression of stem cell biomakers following p $75 \mathrm{NTR}^{\mathrm{vo}}$ ESCs construction. As shown in Figure 1B-1D, compared with empty vector, intergrin $\beta 1$ expression in $\mathrm{p} 75 \mathrm{NTR}^{\mathrm{vo}} \mathrm{ESCs}$ was negative, while CK10 and CK19 expression p75NTR ${ }^{\mathrm{vo}}$ ESCs was positive, indicating that $\mathrm{p} 75 \mathrm{NTR}$ may affect the progression of ESCs.

\section{P75NTR promotes secretion of NGF in ESCs}

Firstly, we used ELISA to detect the expression of NGF in two groups. In the present study, we found that the expression level of NGF was $103.28 \pm 0.88$ in p75NTR ${ }^{\text {vo }}$ ESCs, and $90.42 \pm 0.77$ in EV ESCs, indicating that P75NTR expression in p75NTR ${ }^{\text {vo }}$ ESCs stimulated NGF secretion. In addition, during the wound-healing process among the three groups, at post-operation 14 days, we examined the levels of the NGF proteins, and demonstrated that the $\mathrm{p} 75 \mathrm{NTR}^{\text {vo }}$ ESCs group was able to express more NGF $(122.55 \pm 2.76)$ compared with that $(95.12 \pm 0.98)$ in EV ESCs group $\left({ }^{*} p<0.05\right)$.

\section{P75NTR mediates the proliferation and apoptosis in ESCs}

To evaluate the role of p75NTR expression in ESCs proliferation and apoptosis, P75NTR ${ }^{\mathrm{vo}}$ ESCs were subjected to flow cytometry and CCK-8 assays. Meanwhile, freshly isolated normal ESCs were used as control. We observed that P75NTR ${ }^{\text {vo }}$ ESCs showed a significantly lower apoptosis rate $(0.003 \pm 0.001)$ than EV ESCs $(0.063 \pm 0.011)$ (Figure $2 \mathrm{~A}, p<0.05)$. As expected, P75NTR ${ }^{\text {vo }}$ ESCs also had a significantly higher proliferative capacity $(1.23 \pm 0.13)$ than EV ESCs $(0.72 \pm 0.09)$ (Figure $2 \mathrm{~B}, p<0.05)$. These results indicated that P75NTR mediates the proliferation and apoptosis in ESCs.

\section{P75NTR promotes the migration of ESCs}

To evaluate the effect of p75NTR on ESCs migration, P75NTR ${ }^{\text {vo }}$ ESCs were subjected to transwell invasion assay. And then freshly isolated ESCs were used as control. As shown in Figure 2C, P75NTR vo ESCs showed significantly higher cell migration ability $(251 \pm 32)$ compared with EV ESCs $(157 \pm 63)(p<0.05)$. These data indicated that P75NTR mediates the migration in ESCs.

\section{ERK, JNK and AKT signaling mediates P75NTR pathway}

To clarify which signalling pathways are involved in p75NTR mediated the biology of ESCs, we further investigated the expression of ERK, JNK and AKT. In this study, there are no animals to be sick or dead. We found that the expression of the phosphorylated ERK, JNK and AKT was significantly increased in p75NTR ${ }^{\mathrm{vo}}$ ESCs at 14 day when compared with EV ESCs (Figure 3).

\section{P75NTR promotes wound healing in mice model}

In this work, from 1st to 3rd group, all mice were injected with $500 \mu \mathrm{L}$ of ESCs medium, $500 \mu \mathrm{L}$ of EV ESCs medium, and $500 \mu \mathrm{L}$ of p $75 \mathrm{NTR}^{\mathrm{vo}}$ ESCs medium,

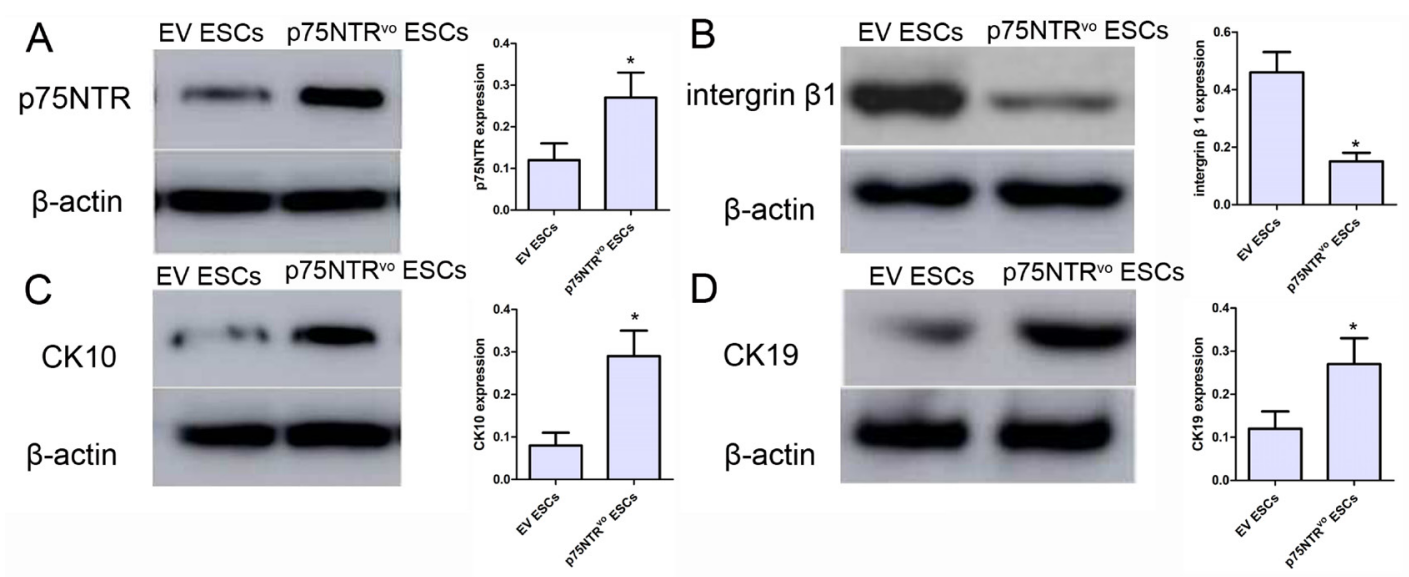

Figure 1: The effect of p75NTR on the expression of ESCs bio-markers. We firstly isolated ESCs from newborn mice. And then, p75NTR ${ }^{\text {vo }}$ ESCs were constructed (A) and subjected to western blot. Compared with empty vector, intergrin $\beta 1$ expression (B) in p75NTR ${ }^{\mathrm{vo}}$ ESCs was negative, while CK10 (C) and CK19 (D) expression p75NTR ${ }^{\mathrm{vo}}$ ESCs was positive. ${ }^{*} p<0.05$, v.s. EV ESCs. 
respectively. The groups were injected on 0,3 day and the area of the wound was measured by tracing the wound on 0, 3, 7 and 14 day post-injury. P75NTR mediated ESCs promoted wound healing. The lesion area of the three groups at day 3, 7, 14 was compared with each other, as shown in Figure 4A. We found that compared with the group injected with EV ESCs, the group injected with p75NTR ${ }^{\text {vo }}$ ESCs increased wound healing area by about $14.86 \%$ at day $3,32.53 \%$ at day 7 and $6.4 \%$ at day 14 . However, there was no significant differences between normal and EV ESCs group $(p>0.05)$. As shown in Figure 4B, we used HE staining to identify that P75NTR promotes wound healing in mice model. Finally, as shown in Figure 4C, western blot further revealed that P75NTR obviously increased the expression of CK10, indicating that P75NTR indeed activate the differentiation of ESCs to promotes wound healing.

\section{DISCUSSION}

As known to all, the epidermis, a kind of selfrenewal tissue, was constructed by multiple compartment layers of keratinocytes. The basal layer is composed of proliferating epidermal stem cells; the upper layers includes viable and differentiation cells; the horny layer comprises terminally differentiated cells [15]. Epidermal homeostasis and stabilization relay on the status of epidermal stem cells situated in the basal layer, which is able to generate newly differentiated cells to replace old cells, such as apoptotic, injured and neucrotic cells. In recent decades, related molecular mechanisms underlying cell differentiation of epidermal stem cells have been extensively investigated [16]. According to our previous study, we assumed that the nerve growth factor may be involved into these processes.

The nerve growth factor contains two kinds of structurally different receptors, p75NTR and the tropomyosin-related kinase A (TrkA). NGF is reported to mediate a wide range of physiological and pathological processes in humans by binding to their receptors. p75NTR, a member of tumor necrosis factor receptor superfamily, comprises three domains, including an extracellular domain, a transmembrane domain, and an intracellular domain. Of three domains, the extracellular domain has four cysteine rich repeats, and is required for interaction of NGF-p75NTR [17-19]. Once NGFp75NTR compounds occur, p75NTR can regulate cell apoptosis, proliferation and differentiation. In the present study, we firstly succeeded to isolate and culture ESCs, and then constructed $\mathrm{p} 75 \mathrm{NTR}^{\mathrm{vo}}$ ESCs from newborn mice. We demonstrated that $\mathrm{p} 75 \mathrm{NTR}$ expression decreased the expression of intergrin $\beta 1$, but increased the expression of CK10 and CK19 compared with those in EV ESCs. Furthermore, we simulated similar environments to the wounded skin tissues using in-vitro p75NTR ${ }^{\text {vo }}$ ESCs. We found that P75NTR obviously promoted cell proliferation and migration, and inhibited cell apoptosis. At the same time, we also demonstrated that P75NTR indeed stimulated the secretion of NGF in ESCs.

Mechanically, ERK signalling pathway plays an important role in regulating the migration of epithelial cells during wound healing [20-22]. When ERK was activated, ERK translocated into the nucleus to regulate cellular proliferation [23, 24]. RhoA-JNK signalling pathway can promote epithelial wound healing by regulating cell survival and protein synthesis $[25,26]$. Dahai $\mathrm{Hu}$ et al. showed that HAESCs accelerated keratinocyte proliferation and migration to promote wound healing via the ERK, JNK, and AKT signal pathways [27]. To clarify which signalling pathways are involved in the differentiation of ESCs, we investigated the specific role of ERK, JNK and AKT signaling pathways in p75NTR vo ESCs. Our data revealed that the expression of p-ERK, p-JNK and p-AKT significantly increased in p75NTR ${ }^{\text {vo }}$ ESCs groups, indicating that ERK, JNK and AKT was involved in p75NTR-mediated ESCs during wound healing. In addition, it has been reported that ERK and AKT signalling can enhance the synthesis and secretion of certain factors, (VEGF, MMP9, et al.) by modulating related transcription factor $[28,29]$. Thus it is plausible that activated ERK and AKT signalling may promote NGF synthesis and secretion in p75NTR ${ }^{\text {vo }}$ ESCs.

In conclusion, we confirmed that p75NTR-mediated ESCs accelerated the wound-healing process and upregulats NGF expression through the $\mathrm{pERK} / \mathrm{ERK}, \mathrm{pJNK} /$ JNK and pAKTK/AKT signalling pathways. Thus, P75NTR may favor skin wound healing in the clinical practice.

\section{MATERIALS AND METHODS}

\section{Cell isolation, culture and transfection}

We isolated ESCs using enzymatic digestion and Col IV rapid adhesion. Briefly, five newborn mice were purchased from the Shandong University Laboratory Animal Centre (Jinan, China). The newborn mice were anesthetized with $25 \%$ pentobarbital sodium $(35 \mathrm{mg} / \mathrm{kg}$ ), shaved backs and wiped with $75 \%$ alcohol. $1 \mathrm{~cm}$ square fresh skin pieces were collected and digested in $0.25 \%$ Dispase (Gibco) at $4^{\circ} \mathrm{C}$, separate the epidermis to digested in $0.25 \%$ protease (Sigma) at $4^{\circ} \mathrm{C}$ overnight. Cells were collected by filtration and centrifuged, and then seeded to a pre-spread with Col IV dish. The keratinocyte serum free medium (K-SFM, Gibco) was added and replaced every other day.

Primary ESCs were separately infected with nerve growth factor (NGFR-p75NTR) lentivirus particles, NGFR-p75NTR-shRNA lentivirus particles and Puro lentivirus particles. Lentivirus particles were obtained from the Genome Ditech Company (Shanghai, China). After the ESCs $\left(1 \times 10^{4} /\right.$ well $)$ were seeded in 96 -well 
plate for 24 hours, cells were co-cultured with $10 \mu \mathrm{L}$ of virus from the three different gradients and polybrene for $8 \mathrm{~h}$, and then the medium should be replaced. Next, cells were observed using an inverted fluorescence microscope (Nikon, Japan) after 3 or 4 days transfection to calculate the transfection efficiency and the multiplicity of infection.

ESCs $\left(1 \times 10^{6}\right.$ cells $\left./ \mathrm{ml}\right)$ were cultured for 3 days. To obtain culture medium from ESCs culture, the medium was changed without FBS and the cells were cultured for 2 days.

\section{Flow cytometry of the cells surface markers}

The Annexin-V-FITC/PE kit (Becton, Dickinson and Company (BD), America) was employed in flow cytometry to probe cellular apoptosis according to the manufacturer's protocol. The cells were collected, washed three times with pre-chilled PBS, and then resuspended in $1 \times$ binding buffer. Cells were stained at room temperature in the dark with $5 \mu \mathrm{L}$ of PE-7-AAD and Annexin-V-FITC for $15 \mathrm{~min}$. Then, another $400 \mu \mathrm{L}$ of $1 \times$ binding buffer was added to each tube before testing. The data was collected and analyzed using FCM (BD LSR Fortessa).

\section{Enzyme-linked immunosorbent assay (ELISA)}

Proteins in ESCs medium were analyzed using ELISA kits (R\&D Systems, USA) to detect the expression of NGF. According to the manufacturer's protocol, NGF in culture medium was collected and measured from ESCs cultures.

\section{Cell counting kit-8}

CCK-8 (Dojindo, Japan) was employed to test cell proliferation. Both normal and stable-transfected cells (approximately $2 \times 10^{3}$ ) were seeded into 96-well plates and cultured for $24 \mathrm{~h}, 48 \mathrm{~h}, 72 \mathrm{~h}, 96 \mathrm{~h}$, respectively. When reached the detected time, $10 \mathrm{ul}$ of CCK- 8 were added into each well and incubated for $1 \mathrm{~h}$ in incubator. The absorbance was measured at the wavelength of $450 \mathrm{~nm}$ used the Multimode Reader (Molecular Devices, MD, American).

\section{In vitro cell migration and metastasis assay}

The non-coated and pre-coated with diluted Matrigel transwell membrane (8.0 um pore size, Corning, USA) were employed to test cell invasion ability. Cells (approximately $5 \times 10^{5}$ ) were suspended in $200 \mathrm{ul}$ epidermal growth factor (EGF)-free medium and seeded on the upper chamber while $700 \mathrm{ul}$ medium contains EGF was added to the lower chamber as an chemo-attract. Incubated $24 \mathrm{~h}$ for migration and $36 \mathrm{~h}$ for metastasis assay. Cells can't invade the membrane were removed by the cotton swab, the membrane was fixed by methanol and
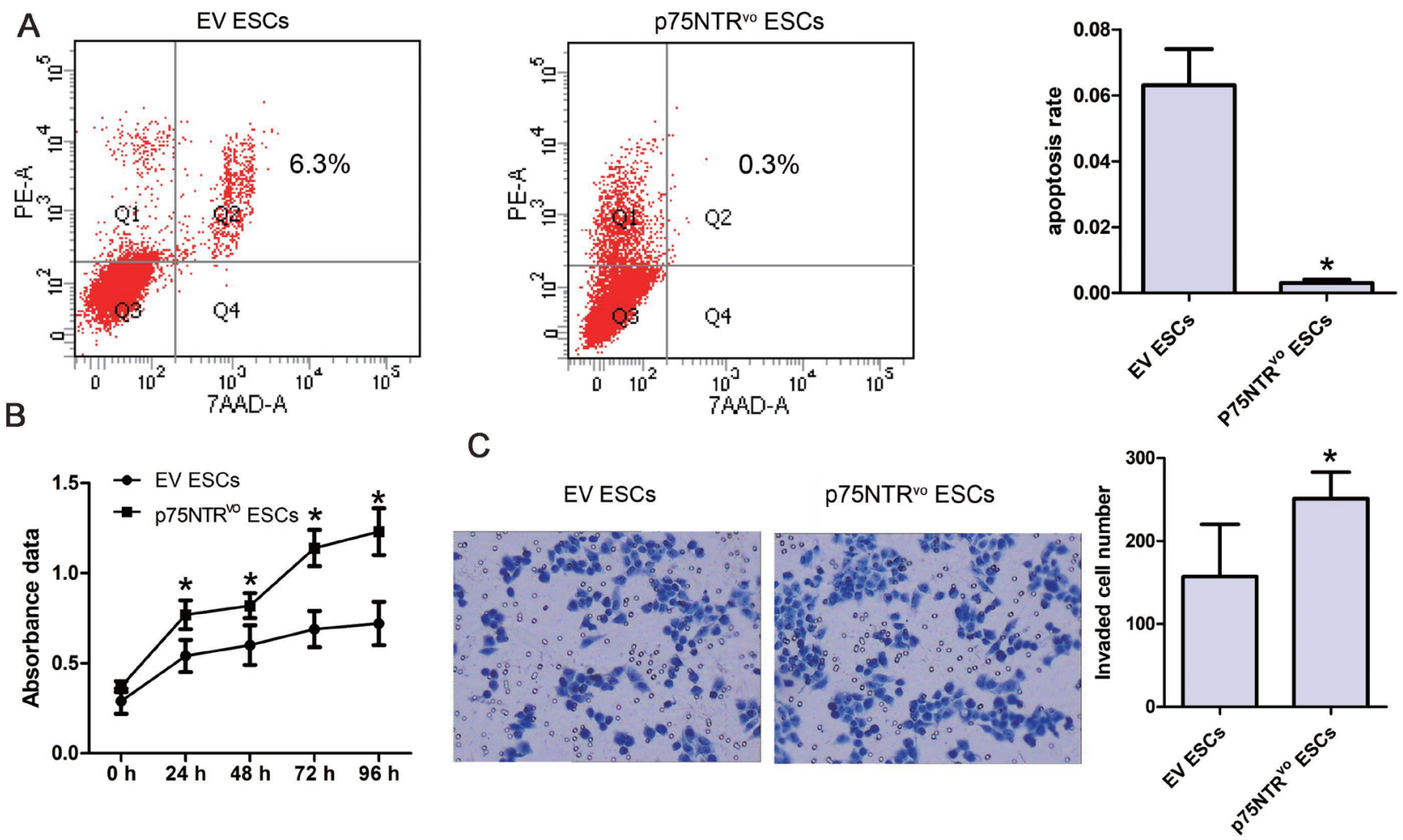

Figure 2: The effects of p75NTR on cell activities of ESCs. (A) The flow cytometry results and data analysis of p75NTR on cell apoptosis. ${ }^{*} p<0.05$, v.s. EV ESCs. (B) The effects of p75NTR on cell proliferation of ESCs. ${ }^{*} p<0.05$, v.s. EV ESCs. (C) The effects of p75NTR on cell migration ability of ESCs. ${ }^{*} p<0.05$, v.s. EV ESCs. 
stained with haematoxylin. The number of the invaded cells was calculated by counting five random fields under the microscope.

\section{Protein isolation and western blotting}

Radio immunoprecipitation assay (RIPA) buffer containing phenylmethanesulfonyl fluoride (PMSF) (PMSF: RIPA $=1: 100)$ and bicinchoninic acid (BCA) protein assay kit (Beyotime, China) were respectively employed to extract protein and determine the concentration of protein. A total of $40 \mu \mathrm{g}$ of protein was added and separated on a $6 \%$ and $10 \%$ sodium dodecyl sulfate polyacrylamide gel electrophoresis (SDS-PAGE) gel. Next, the separated protein bands were then transferred to a nitrocellulose membrane, which was blocked with $5 \%$ powdered milk for $1 \mathrm{~h}$ at room temperature. In the tests of cells, the membranes were incubated with the following primary antibodies: p44/42 (ERK1/2, 1:1000, \#9102, Cell Signaling Technology [CST]), phospho p44/42 (pERK1/2,
1:1000, \#9101, CST), JNK (JNK1/2, 1:1000, \#9258, CST), phospho JNK (Thr183/Tyr185, 1:1000, \#4668s, CST), AKT (1:1000, \#4691, CST), phospho AKT (1:1000, Ser473, \#9271, CST) at $4^{\circ} \mathrm{C}$ overnight. After washing, the membranes were incubated with the corresponding secondary antibodies at room temperature for $1 \mathrm{~h}$. The expression levels were detected and analyzed with the Super Signal West Pico Chemiluminescent Substrate (LAS4000mini, Fuji Company, Japan).

\section{In vivo experiments in mice}

C57BL/6 mice (6 weeks old, male, 20-25 g) were purchased from the Shandong University Laboratory Animal Centre (Jinan, China). The mice were randomly divided into three groups $(n=6)$ and housed in a pathogenfree barrier facility. After mice were anesthetized with $25 \%$ pentobarbital sodium (35 mg/kg), their backs were shaved and wiped with $75 \%$ alcohol. Full-thick skins measuring $1 \mathrm{~cm} \times 1 \mathrm{~cm}$ were cut to create the wound model. The mice
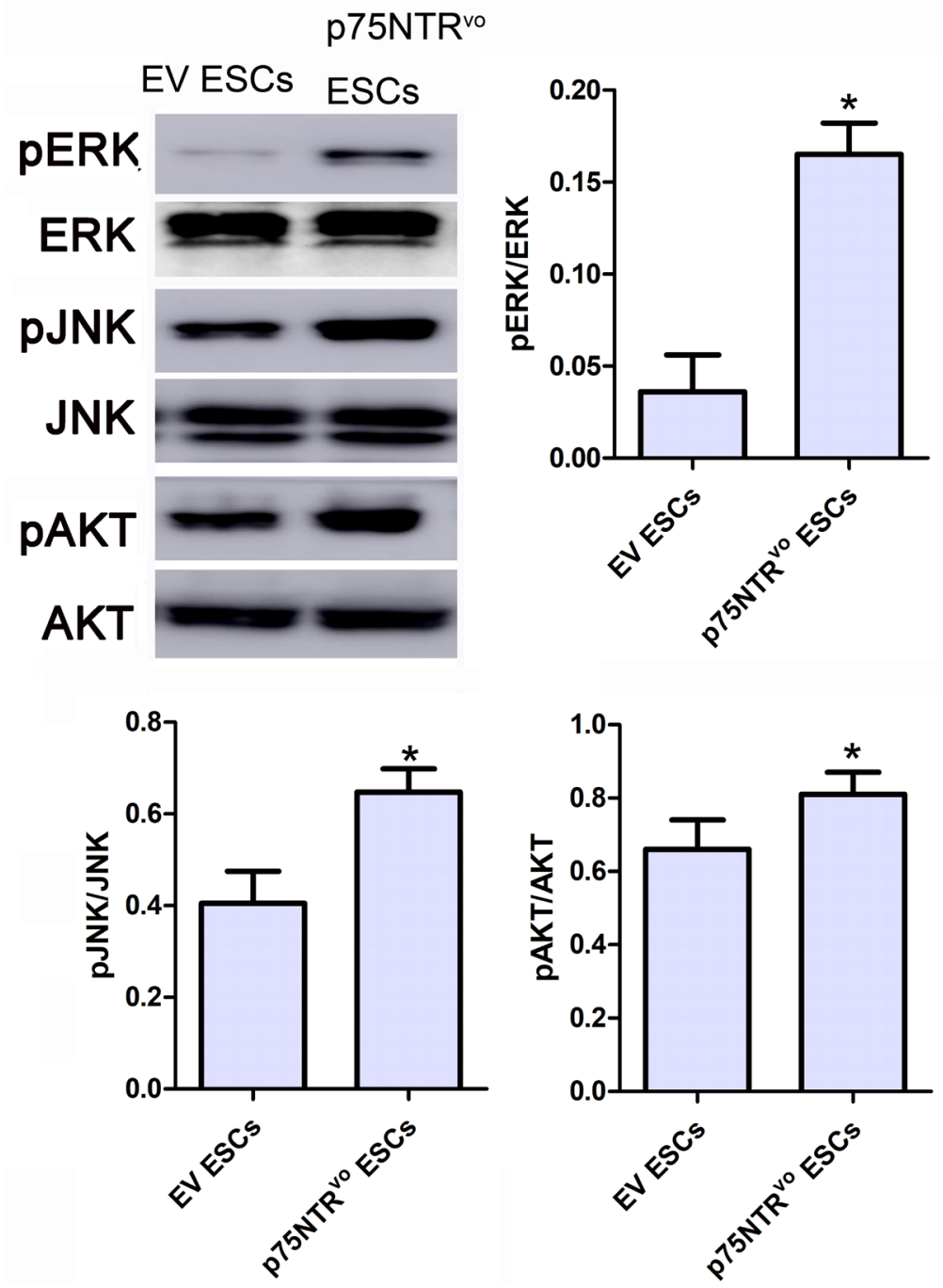

Figure 3: The expressions of ERK, JNK and AKT in EV ESCs and p75NTR ${ }^{\text {vo }}$ ESCs. $^{*} p<0.05$, v.s. EV ESCs. 


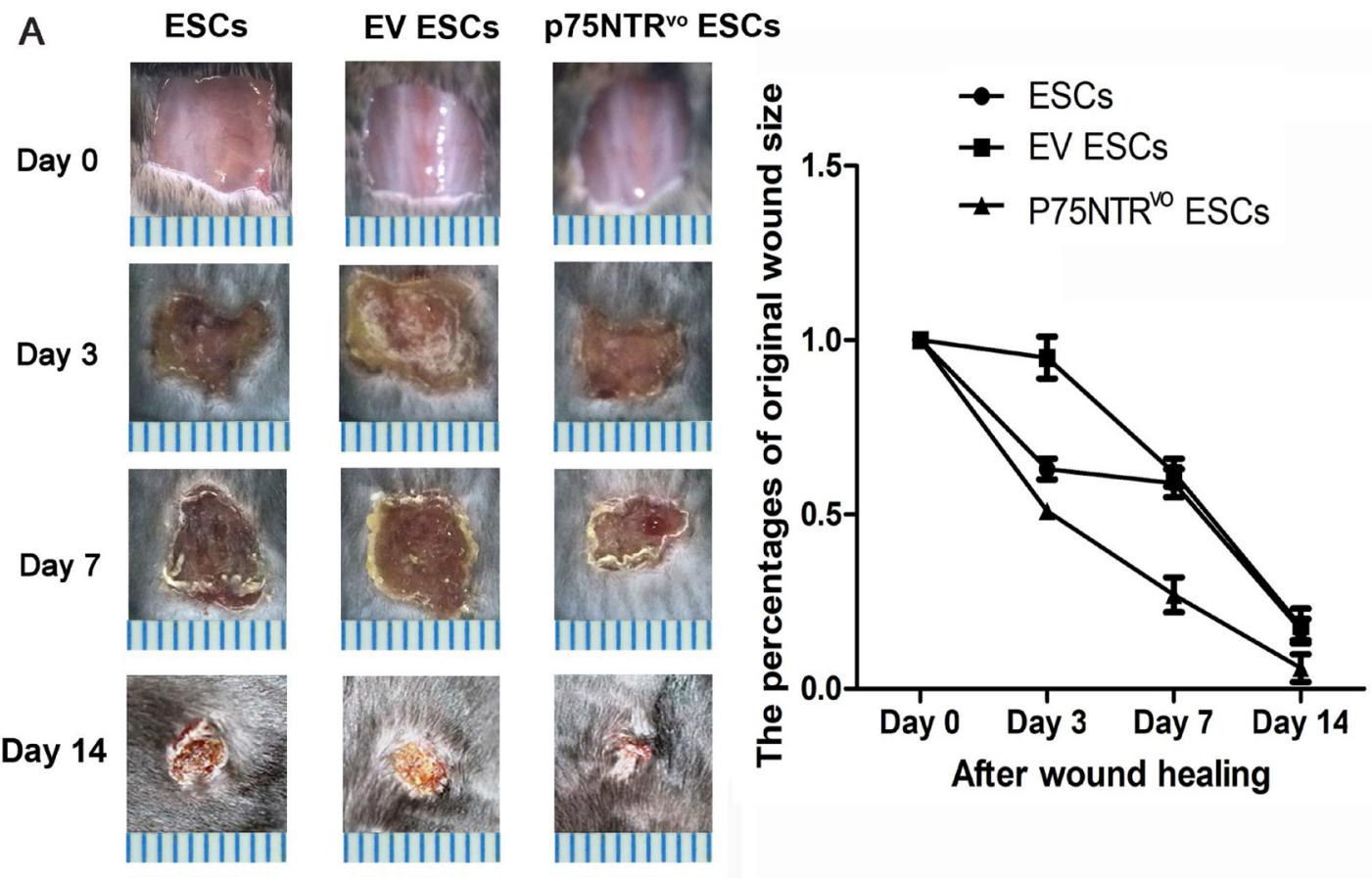

B

ESCs

EV ESCs

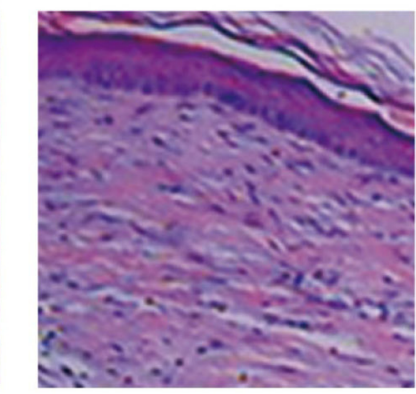

p75NTR ${ }^{\text {vo }}$ ESCs
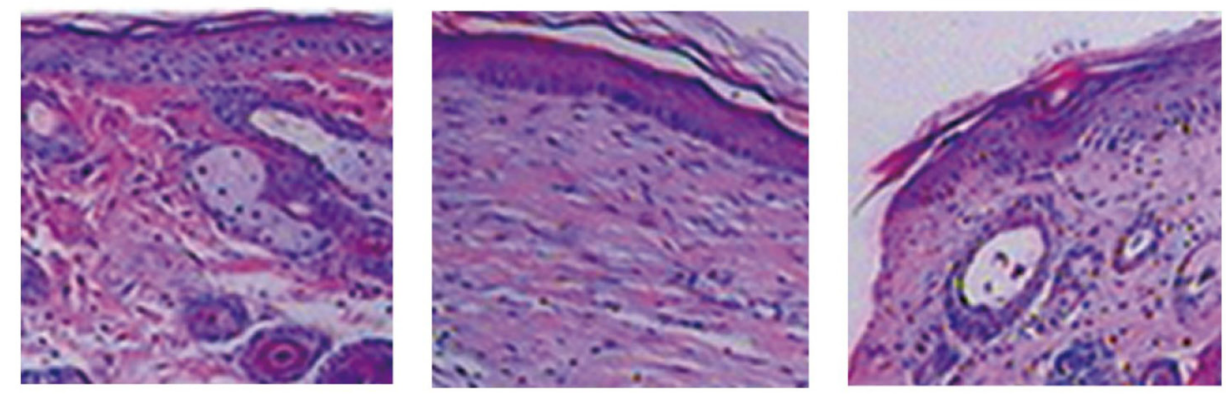

C

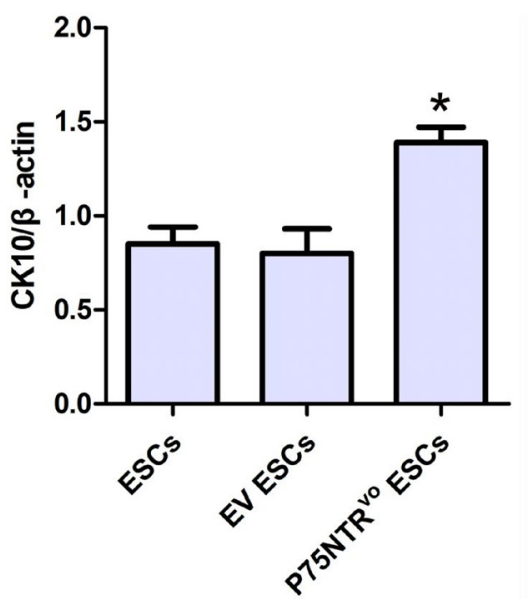

Figure 4: Wound closure status in normal ESCs, empty vector (EV) ESCs and p75NTRvo ESCs in mice model. (A) Representative photographs of skin full-thick excision wounds in mice treated with ESCs, PBS-treated control and $\mathrm{p} 75 \mathrm{NTR}^{\mathrm{vo}} \mathrm{ESCs}$ for 0,3 , 7 and 14 days. ${ }^{*} p<0.05$, compared to EV ESCs groups; $n=5$. (B) The HE staining in normal ESCs, EV ESCs and p75NTR ${ }^{\text {vo }}$ ESCs at day 14. (C) The expressions of CK10 were detected using western blot in normal ESCs, EV ESCs and p75NTR ${ }^{\text {vo }}$ ESCs on day 14 . ${ }^{*} p<0.05$, v.s. EV ESCs. 
were revived by the mice by intraperitoneal injection of $5 \mathrm{~mL}$ lactated Ringer's liquid immediately. From 1st to 3rd group, the mice were respectively injected with $500 \mu \mathrm{L}$ of ESCs medium, $500 \mu \mathrm{L}$ of EV ESCs medium and $500 \mu \mathrm{L}$ of p75NTRvo ESCs medium. The groups were injected on 0,3 day and the area of the wound was measured by tracing the wound on $0,3,7$ and 14 day post-injury. The wound area of the seven groups on 3, 7, 14 day was compared with which of their own on 0 day by a metric ruler measure. (Wound area rate of $(3,7,14) \mathrm{D}) \%=($ the wound area of $(3,7,14) \mathrm{D}) /($ the wound area of 0 D). Use a metric ruler to measure the area of the wound.

\section{Statistical analysis}

The SPSS 17.0 software was used to perform the statistical analyses and the data were expressed as the mean \pm standard deviation (SD). Student's $t$ test was applied to perform the intergroup comparison and analysis of variance (ANOVA) was used to compare multiple groups. $P<0.05$ was considered statistically significant.

\section{CONFLICTS OF INTEREST}

None.

\section{FUNDING}

This work was greatly supported by the National Natural Science Foundation of China (No. 81571911, 81772092).

\section{REFERENCES}

1. Yates CC, Rodrigues M, Nuschke A, Johnson ZI, Whaley D, Stolz D, Newsome J, Wells A. Multipotent stromal cells/mesenchymal stem cells and fibroblasts combine to minimize skin hypertrophic scarring. Stem Cell Res Ther. 2017; 8:193.

2. Strong AL, Neumeister MW, Levi B. Stem Cells and Tissue Engineering: Regeneration of the Skin and Its Contents. Clin Plast Surg. 2017; 44:635-650.

3. Huang S, Rompolas P. Two-photon microscopy for intracutaneous imaging of stem cell activity in mice. Exp Dermatol. 2017; 26:379-383.

4. Shaw TJ, Martin P. Wound repair: a showcase for cell plasticity and migration. Curr Opin Cell Biol. 2016; 42:29-37.

5. Simkin J, Sammarco MC, Dawson LA, Schanes PP, Yu L, Muneoka K. The mammalian blastema: regeneration at our fingertips. Regeneration(Oxf). 2015; 2:93-105.
6. Ali N, Hosseini M, Vainio S, Taïeb A, Cario-André M, Rezvani HR. Skin equivalents: skin from reconstructions as models to study skin development and diseases. Br J Dermatol. 2015; 173:391-403.

7. Choi HR, Byun SY, Kwon SH, Park KC. Niche interactions in epidermal stem cells. World J Stem Cells. 2015; 7:495-501.

8. Markeson D, Pleat JM, Sharpe JR, Harris AL, Seifalian AM, Watt SM. Scarring, stem cells, scaffolds and skin repair. J Tissue Eng Regen Med. 2015; 9:649-68.

9. Alibardi L. Histochemical, Biochemical and Cell Biological aspects of tail regeneration in lizard, an amniote model for studies on tissue regeneration. Prog Histochem Cytochem. 2014; 48:143-244.

10. Leggett CL, Gorospe EC, Lutzke L, Anderson M, Wang KK. A new era: endoscopic tissue transplantation. Curr Opin Gastroenterol. 2013; 29:495-500.

11. Evans ND, Oreffo RO, Healy E, Thurner PJ, Man YH. Epithelial mechanobiology, skin wound healing, and the stem cell niche. J Mech Behav Biomed Mater. 2013; 28:397-409.

12. Balaji S, Keswani SG, Crombleholme TM. The Role of Mesenchymal Stem Cells in the Regenerative Wound Healing Phenotype. Adv Wound Care (New Rochelle). 2012; 1:159-165.

13. Martínez-Santamaría L, Guerrero-Aspizua S, Del Río M. Skin bioengineering: preclinical and clinical applications. Actas Dermosifiliogr. 2012; 103:5-11

14. Wang X, Tredget EE, Wu Y. Dynamic signals for hair follicle development and regeneration. Stem Cells Dev. 2012; 21:7-18.

15. Micera A, Puxeddu I, Balzamino BO, Bonini S, LeviSchaffer F. Chronic nerve growth factor exposure increases apoptosis in a model of in vitro induced conjunctival myofibroblasts. PLoS one. 2012; 7:e47316.

16. Fuchs E. Chapter nineteen-Epithelial Skin Biology: Three Decades of Developmental Biology, a Hundred Questions Answered and a Thousand New Ones to Address. Curr Top Dev Biol. 2016; 116:357-374.

17. Okumura $\mathrm{T}$, Shimada $\mathrm{Y}$, Imamura $\mathrm{M}$, Yasumoto $\mathrm{S}$. Neurotrophin receptor p75(NTR) characterizes human esophageal keratinocyte stem cells in vitro. Oncogene. 2003; 22:4017-26.

18. Iwata Y, Akamatsu H, Hasegawa S, Takahashi M, Yagami A, Nakata S, Matsunaga K. The epidermal Integrin beta-1 and p75NTR positive cells proliferating and migrating during wound healing produce various growth factors, while the expression of $\mathrm{p} 75 \mathrm{NTR}$ is decreased in patients with chronic skin ulcers. J Dermatol Sci. 2013; 71:122-9.

19. Truzzi F, Saltari A, Palazzo E, Lotti R, Petrachi T, Dallaglio K, Gemelli C, Grisendi G, Dominici M, Pincelli C, Marconi 
A. CD271 mediates stem cells to early progeny transition in human epidermis. J Invest Dermatol. 2015; 135:786-795.

20. Matsubayashi Y, Ebisuya M, Honjoh S, Nishida E. ERK activation propagates in epithelial cell sheets and regulates their migration during wound healing. Curr Biol. 2004; 14:731-5.

21. Kanaji N, Nelson A, Wang X, Sato T, Nakanishi M, Gunji Y, Basma H, Michalski J, Farid M, Rennard SI, Liu X. Differential roles of JNK, ERK1/2, and p38 mitogenactivated protein kinases on endothelial cell tissue repair functions in response to tumor necrosis factor-alpha. J Vasc Res. 2013; 50:145-56.

22. Zhang M, Sun L, Wang X, Chen S, Kong Y, Liu N, Chen Y, Jia Q, Zhang L, Zhang L. Activin B promotes BMSCmediated cutaneous wound healing by regulating cell migration via the JNK-ERK signaling pathway. Cell Transplant. 2014; 23:1061-1073.

23. Saltiel AR, Kahn CR. Insulin signalling and the regulation of glucose and lipid metabolism. Nature. 2001; 414:799-806.

24. Boulton TG, Nye SH, Robbins DJ, Ip NY, Radziejewska E, Morgenbesser SD, DePinho RA, Panayotatos N, Cobb MH, Yancopoulos GD. ERKs: a family of proteinserine/threonine kinases that are activated and tyrosine phosphorylated in response to insulin and NGF. Cell. 1991; 65:663-75.
25. Zhang M, Liu NY, Wang XE, Chen YH, Li QL, Lu KR, Sun L, Jia Q, Zhang L, Zhang L. Activin B promotes epithelial wound healing in vivo through RhoA-JNK signaling pathway. PLoS one. 2011; 6:e25143.

26. Lima MH, Caricilli AM, de Abreu LL, Araújo EP, Pelegrinelli FF, Thirone AC, Tsukumo DM, Pessoa AF, dos Santos MF, de Moraes MA, Carvalheira JB, Velloso LA, Saad MJ. Topical insulin accelerates wound healing in diabetes by enhancing the AKT and ERK pathways: a double-blind placebo-controlled clinical trial. PloS one. 2012; 7:e36974.

27. Zhao B, Liu JQ, Zheng Z, Zhang J, Wang SY, Han SC, Zhou Q, Guan H, Li C, Su LL, Hu DH. Human amniotic epithelial stem cells promote wound healing by facilitating migration and proliferation of keratinocytes via ERK, JNK and AKT signaling pathways. Cell Tissue Res. 2016; 365:85-99.

28. Wang J, He C, Zhou T, Huang Z, Zhou L, Liu X. NGF increases VEGF expression and promotes cell proliferation via ERK1/2 and AKT signaling in Müller cells. Mol Vis. 2016; 22:254-63.

29. Cho SJ, Chae MJ, Shin BK, Kim HK, Kim A. Akt- and MAPK-mediated activation and secretion of MMP-9 into stroma in breast cancer cells upon heregulin treatment. Mol Med Rep. 2008; 1:83-8. 